\title{
Influence of hyperbaric oxygenation treatment (HBOT) on clinical outcomes (recurrent myocardial infarction and survival rate) during five-year monitoring period after acute myocardial infarction
}

\author{
Eduard Dotsenko $^{1^{*}}$, Dmitry Salivonchyk ${ }^{2}$, Osain Menizibeya Welcome ${ }^{1}$, \\ Konstantin Dotsenko ${ }^{1}$, Sergei Salivonchyk ${ }^{2}$, Valery Bobkov ${ }^{1}$, Natalia Nikulina ${ }^{1}$, \\ Eugenia Semeniago $^{2}$, Svetlana Nerobeeva ${ }^{1}$ \\ ${ }^{1}$ Belarusian State Medical University, Minsk, Belarus; *Corresponding Author: ed_dots@mail.ru \\ ${ }^{2}$ Gomel State Medical University, Gomel, Belarus
}

Received 17 November 2013; revised 25 December 2013; accepted 5 January 2014

Copyright (C 2014 Eduard Dotsenko et al. This is an open access article distributed under the Creative Commons Attribution License, which permits unrestricted use, distribution, and reproduction in any medium, provided the original work is properly cited. In accordance of the Creative Commons Attribution License all Copyrights @ 2014 are reserved for SCIRP and the owner of the intellectual property Eduard Dotsenko et al. All Copyright (C) 2014 are guarded by law and by SCIRP as a guardian.

\section{ABSTRACT}

Surgical treatments of acute myocardial infarction (MI) possess a high clinical effectiveness, but there are fixed limitations, related to the patient's state, which are limited by medical resources and organizational problems. The development of new medical technologies provides a better and effective non-surgical treatment of acute $\mathrm{MI}$ and increases long-term prognosis in this category of patients. The study aims to investigate the influence of hyperbaric oxygenation treatment on clinical outcomes (survival rate and recurrent myocardial infarction (rMI)) during the five-year period of monitoring. The study involved 697 patients who suffered from acute $\mathrm{MI}$, having undergone the standard treatment. The patients were randomly divided into two groups: Group 1 (reference, $n=363$ ); Group 2 (test, $n=334$ ). Patients of Group 2 were given the traditional treatment, accompanied with HBOT (isopression for forty minutes at a working pressure of $0.03 \mathrm{MPa}$ ). HBOT was applied first through the fifth day following MI. The treatment course included six cycles, once per day. The clinical assessment was focused on clinical outcome: rMI and mortality related to cardiovascular events. HBOT application that accompanied the acute MI with traditional pharmacotherapy has been proved to reduce rMI within five years following inpatient discharge ( $\mathrm{rMI}$ rate was $14 \%$ in the reference group and $5.4 \%$ in the test group, $\left.x^{2}=13.3, p<0.05\right)$. The combination of HBOT with traditional methods in treating acute MI makes it possible to raise the five-year survival rate from $84.4 \%$ up to $95.9 \%$.

\section{KEYWORDS}

Hyperbaric Oxygenation Treatment; Myocardial Infarction; Recurrent Myocardial Infarction; Clinical Outcomes; Mortality Rate; Survival Rate

\section{INTRODUCTION}

Myocardial infarction (MI) is still considered one of the most dangerous complications of atherosclerosis, causing high mortality rates in several groups of patients [15]. Several bodies of evidences indicate a decrease in cases of cardiovascular mortality in developed countries in the last decade. Approximately 20\% - 30\% accounting for this decrease is due to the better quality of medical measures, while the remaining $70 \%-80 \%$ reflects the effectiveness of rehabilitation program on primary prophylactics of atherosclerosis [6-8]. However, the effectiveness of the secondary prophylactics of atherosclerosis is lower and, particularly, the post-MI survivors retain the risky "hallmark" for recurrent myocardial infarction (rMI) and cardiovascular related mortality $[9,10]$. Moreover, while acute MI inpatient treatment methods can be assumed to have progressed immensely, the MI outpatient treatment achievements are still much to be desired.

Retrospective studies of over 5000 acute MI hospital patients in the USA for two decades (1975-1995) con- 
firmed that rMI eventuality and mortality within a year following inpatient discharge did not tend to change in any way since the late 80 s of the last century [11]: the first-year mortality rate was limited to $10 \%-13 \%$, the second-year mortality rate-17\% - 19\%. As reported [12], the total mortality rate of Scottish post-MI patients within the first year counted $31.4 \%$, reaching $64.0 \%$ within a 10 -year period. In a study of Swedish MI patients, the frequency of rMI within a 5-year period was $28 \%$, and reaching $37 \%$ within a 10 -year period [13]. The total mortality within a 5-year period was $19 \%$, and within a 10-year period-33\% [14]. Launbjerg et al. reported similar results in a Danish population [10]. According to Madsen et al. [15], the frequency of rMI after medication was $10.5 \%$ (during a 2.4-year observation time), which corresponds with the results obtained in the American population [16]. The findings of Vaccarino et al. indicate that in USA, mortality within a 2-year period after MI was 28.9\% among females and 19.6\% among males [16]. The situation in developed countries has markedly improved in the new millennium. However, the problem of rMI eventuality and cardiovascular mortality in patients with acute rMI remains relevant.

The post-infarction period is influenced by a number of factors, including clinical peculiarities of each acute MI case, risk factors (if any), patient's adaptability to the treatment etc. However, there is an unshakable dogma for early myocardial ischemia treatment to be a prerequisite for more favorable clinical course. In this regard, the use of oxygenation technology has gained an increasing prominence [17-19].

The oxygenation technology applied for ischemic heart therapy is based on the idea that blood oxygen partial pressure increase provides elimination of tissue hypoxia $[18,19]$. Starting from the 1940s, patients were efficiently treated with normobaric oxygenation; a bit later hyperbaric oxygenation (HBOT) technology was introduced [2022]. The technology of hyperbaric medicine is effective for the treatment of ischemic brain damage [23,24], carbon monoxide poisoning [25], and a number of other clinical conditions [26,27]. Unfortunately, the technology failed to be widely used for some reasons. Firstly, HBOT does not provide "on-the-spot" clinical effect, as compared to drug therapy. Besides, our medicine is traditionally oriented on giving more rest for MI patients, thus, protecting them from any outer impacts, including equipment-related manipulations. Finally, we have no established clinical practice of long-term monitoring for MI-suffered patients and for those treated with HBOT $[28,29]$. Nowadays, oxygen therapy (of any variant) is regarded more like a tradition, well-founded by pathophysiologists rather than clinical practitioners.

The aim of this study was to investigate the influence of hyperbaric oxygenation treatment on clinical out- comes (recurrent myocardial infarction and survival rate) during a 5-year monitoring period.

\section{SUBJECTS AND METHODS}

The study was open, prospective, and randomized. It was conducted during 2005-2009 years in the cardiology hospital of Gomel region. The commission for medical ethics found no inconformity to the medical ethics and morality standards.

Inclusion criteria: The first myocardial infarction diagnosed verified by clinical, ECG and biochemical analyses [30-32]; MI of at least one-day history and at most five days history; age of patients between 30 and 75 years; informed consent to participate in the study; approval by the commission for medical ethics. Exclusion criteria: MI after 5-day history; right ventricular infarction; claustrophobia; oncology anamnesis; psychic disturbances; alcohol and/or drug abuse; refusal to participate; acute ear, nose, throat diseases; unstable hemodynamics (persistent pain syndrome, negative dynamics in ECG and laboratory analyses).

The study involved 697 MI patients. Treatment regimen of MI-patients corresponded to standard recommendation [33] and included the myocardial revascularization technique according to indications (thrombolysis, angioplasty, coronary stenting and coronary artery bypass surgery) and drug therapy. The standard drug therapy included aspirin, heparin, beta-blockers, ACE inhibitors, nitroglycerin, some patients were additionally treated with antiarrhythmic and hemodynamic preparations [33]. The patients were randomized into two groups: Group 1 (reference, $\mathrm{n}=363$; 274 males and 89 females, mean age of $56.4 \pm 11.7$ years); Group 2 (test, $\mathrm{n}=334$; 266 males and 68 females, mean age of $55.5 \pm 8.2$ years) (Tables $1-3$ ). Patients of Group 2 were given the traditional treatment, accompanied with standard HBOT using the BLKS-307 (Russia, Moscow) single-seat apparatus (isopression for 40 minutes at a working pressure of $0.03 \mathrm{MPa}$ ). HBOT commenced on the first through the fifth day (average2.3 days) following the MI; the treatment course included 6 cycles, once per day.

The groups were homogeneous in both socio-demographic parameters (Table 1 ) and clinical characteristics (Table 2). Thus, Q-wave-MI in Group 1 and 2 amounted to $71.4 \%$ and $79.3 \%$ respectively, anterior MI localization was found in $52.6 \%$ and $48.8 \%$ of patients, and thrombolysis was applied to $17.9 \%$ and $21.6 \%$ of the

Table 1. Gender and demographic characteristics of MI investigated patients, $\mathrm{n}(\%, \mathrm{M} \pm \mathrm{m})$.

\begin{tabular}{cccc}
\hline & Males & Females & Age (years) \\
\hline Group 1, $\mathrm{n}=363$ & $274(75.5 \pm 2.3)$ & $89(24.5 \pm 2.3)$ & $56.4 \pm 11.7$ \\
Group 2, $\mathrm{n}=334$ & $266(79.6 \pm 2.2)$ & $68(20.4 \pm 2.2)$ & $55.5 \pm 8.2$ \\
\hline
\end{tabular}


Tab le 2. Clinical peculiarities of diseases, concomitant pathology among MI investigated patients, $\mathrm{n}(\%, \mathrm{M} \pm \mathrm{m})$.

\begin{tabular}{ccc}
\hline & Group 1 & Group 2 \\
\hline Non-Q-wave-MI & $104(28.6 \pm 2.4)$ & $69(20.7 \pm 2.2)$ \\
Q-wave-MI & $259(71.4 \pm 2.4)$ & \\
\hline Anterior MI & $172.3 \pm 2.2)$ \\
\hline Inferior MI & Localization & $171(51.2 \pm 2.7)$ \\
Myocardial revascularization, including: & $191(52.6 \pm 2.6)$ & $163(48.8 \pm 2.7)$ \\
Coronary artery bypass surgery & $138(38.0 \pm 2.6)$ & $141(42.2 \pm 2.7)$ \\
Stenting & $49(13.5 \pm 1.8)$ & $49(14.7 \pm 1.9)$ \\
Thrombolysis & $33(9.1 \pm 1.5)$ & $62(18.6 \pm 2.1)$ \\
\hline & $65(17.9 \pm 2.0)$ & $72(21.6 \pm 2.3)$ \\
\hline Arterial hypertension & $214(64.1 \pm 2.6)$ \\
Diabetes mellitus & Concomitant pathology & $44(13.2 \pm 1.9)$ \\
Dislipidemia & $242(66.7 \pm 2.5)$ & $230(68.9 \pm 2.5)$
\end{tabular}

Table 3. Frequency of complications of MI investigated patients, $\mathrm{n}(\%, \mathrm{M} \pm \mathrm{m})$.

\begin{tabular}{ccc}
\hline MI complications & Group 1 & Group 2 \\
\hline Heart rhythm disturbance & $40(11.0 \pm 0.7)$ & $34(10.2 \pm 0.7)$ \\
Conductivity disturbance & $36(9.9 \pm 0.4)$ & $30(9.0 \pm 0.5)$ \\
Formation of aneurysm & $19(5.2 \pm 0.2)$ & $13(3.9 \pm 0.1)$ \\
Acute left ventricular failure & $14(3.9 \pm 0.3)$ & $11(3.3 \pm 0.3)$ \\
Cardiogenic shock & $3(0.8 \pm 0.2)$ & $5(1.5 \pm 0.2)$ \\
Ventricular fibrillation & $2(0.6 \pm 0.2)$ & $1(0.3)$ \\
Pulmonary embolism & $2(0.6 \pm 0.2)$ & $2(0.6 \pm 0.2)$ \\
Apparent death & $1(0.3 \pm 0.1)$ & $6(1.8 \pm 0.2)$ \\
\hline
\end{tabular}

cases respectively (Table 2).

The clinical assessment was focused on rMI and cardiovascular related mortality rate, as referenced by medical histories, outpatient cards, and death certificates. Monitoring duration was 5 years. Statistical data processing was carried out by nonparametric methods using the Pearson criterion, $\chi^{2}$ and Fischer's exact test.

\section{RESULTS}

When applying HBOT, no substantial or life-menacing complications were observed in Group-2 patients. PostMI patients of both groups were discharged in good state of health to follow their sanatorium and spa treatment. Forty two $(n=42)$ patients from the first group and 18 patients from the second group were excluded from the study due to the absence of information concerning their life-status (dead/alive) after 5 years of beginning the research (see Table 4 for the clinical history during the 5 -year monitoring period). Thus by the end of the study, we had information on 321 patient from reference group and 316 patients from the test group.

rMI was reported mainly in male patients (86\% and $75 \%$ of reference and test groups respectively), having anterior MI localization (86\% of the reference group, $75 \%$ of the test group). Male mortality also prevailed
Table 4. The rate of clinical outcome in the study groups.

\begin{tabular}{ccc}
\hline \multirow{2}{*}{ Parameters } & Group 1 (reference) & Group 2 (test) \\
\cline { 2 - 3 } & $n$ & $n$ \\
\hline Included & 363 & 334 \\
$\begin{array}{c}\text { Excluded } \\
\text { (after 5 years) } \\
\text { rMI }\end{array}$ & 92 (No data - 42; M - 50*) & 31 (No data - 18; M - 13) \\
\hline
\end{tabular}

Nota Bene: $\mathrm{n}$-number of participants; ${ }^{*}$ Differences are valid for the 5 -year monitoring, $\chi^{2}$ criterion being applied. Among the excluded after 5 years, there was no data for 42 in the reference group and 18 in the test group. Mortality (M) was higher in the reference group $\left(\chi^{2}=13.3, p=0.00\right)$. The cases of recurrent myocardial infarction (rMI) were higher in the reference group, compared to the test group $\left(\chi^{2}=13.3, p=0.00\right)$.

( $75 \%$ and $50 \%$ of reference and test groups respectively), with MI anterior localization (75\% of the reference group, $50 \%$ of the test group). Eighty three percent (83\%) of the patients of both groups were deceased within the first 12 months of monitoring. Our results are similar to the data previously reported by Goldberg et al. [11] and Capewell et al. [12].

Overall, the 5-year outcome is rather contrasting: rMI was reported in 45 patients of the reference group (14.0\%), as compared to 17 patients of the test group (5.4\%). The $\chi^{2}$ criterion was applied to prove statistically, the considerable decrease in rMI eventuality in HBOT-treated patients during the 5-year period following acute MI $\left(\chi^{2}\right.$ $=13.3, \mathrm{p}=0.00$ ).

As we have shown earlier the rate of rMI in patients, who received HBOT as additional treatment, was significantly lower, than those, who did not. At the same time, rMI within the 2-year period was remarkably unbalanced: the first 6 months following acute MI is found to be the most unfavorable [34]. The results of this present research confirm our previous data [34], but with a very much higher statistical significance.

Similarly, during the study period, 50 MI-suffered patients of the reference group were deceased due to comorbidity (from total causes) (survival rate-84.4\%). 
When treating with HBOT, 13 patients were deceased during 5 years, also from total causes (survival rate$95.9 \%)$. In the previous study [34], the 2-year survival rate was $86.2 \%$ for the reference group and $94.7 \%$ for the test group. However, the difference was found to be statistically invalid $(p>0.05)$. This was probably due to uneven distribution of mortality cases within the 2-year monitoring period. In the present study, statistical power was much higher; we managed to gain statistical difference $\left.\chi^{2}=23.1, p<0.05\right)$. However, we should mention that time inequality had played a role: mortality was at its peak during the first 6 months after the MI.

\section{DISCUSSION}

In general, application of hyperbaric oxygen to acute MI treatment provides for rMI reduction (by $\sim 8 \%$ ) and 5 -year survival rate increase $(\sim 11 \%)$ in post-MI patients. In discussing the study outcome, it is essential to pay special attention to some conditions. First, rMI eventuality and post-MI mortality rate in the reference group patients are similar to the generally known information $[7,10,12,16]$; some differences may be found due to peculiarities of the group organized, which is subject to exclusion criteria. The first half-year following acute MI attack is also well known to be the most life-dangerous period.

Presently, the question about hyperbaric oxygenation application for the treatment of MI remains controversial [21]. Our results confirm the point of view, that early HBOT application in MI patients, results in faster eradication of misbalanced oxygen myocardial need and delivery, which contributes to MI area reduction, scar healing with "softer" collagen tissue, aneurysm prevention $[28,35]$. It has been demonstrated in an experimental condition that the influence of hyperbaric oxygenation prevents the development of hypercoagulation syndrome [36], HBOT application immediately after coronary occlusion reduces myocardial necrosis and acute mortality in rats [37]. The beneficial effects of HBOT in treating ischemia-related wounds may be mediated by stimulating angiogenesis [27]. In addition, HBOT effects are characterized with concentration reduction of adrenaline, noradrenaline, biogenic amines, by myocardial electric homogeneity stabilization, by increased antioxidative protection followed by lipid reduced peroxidation and cytoprotection in early monitoring period $[15,18,19,28,38]$. On the other hand, results of experiment reveal that the use of HBOT induces catalase-activity and reduces infarct size in ischemic rat myocardium [39]. After 6 - 8 months, HBOT adaptation effects fade, and HBOTtreated post-MI patients' rMI and survival rate tend to demonstrate similar characteristics, as compared to patients treated with traditional pharmacotherapy.
In other words, HBOT is indispensable for the first half-year following MI to reduce rMI and increase the survival rate. We have used HBOT at a pressure lower than in traditionally applied ones (0.03 MPa). We opine that use of excessive dosage of oxygen $(0.1 \mathrm{MPa})$ is irrelevant, in particular due to the activation of lipoperoxidation [40].

Ultimately, we are unable to make the decisive assessment on the data obtained by this study. However, the test group patients' lives actually saved can serve a good recommendation to introduce HBOT therapy, at least to treat acute MI, subject to patients' strict selection. Any further investigations might benefit specific clinical practice and experience in this issue.

A systematic review of hyperbaric oxygen therapy for acute coronary syndrome in the Cochrane Database showed that HBOT followed by an episode of acute coronary syndrome reduces the risk of death, re-infarction, dysrhythmias. However, the small number of studies, the modest numbers of patients, and the methodological and reporting inadequacies of the primary studies demand a cautious interpretation. Thus, the adjunctive application of HBOT in these patients cannot be recommended to be introduced into routine clinical practice [41].

\section{CONCLUSION}

In conclusion, the present study showed that HBOT application that accompanied the acute MI traditional pharmacotherapy was proved to reduce rMI within 5 years following inpatient discharge (rate of rMI was $14 \%$ in the reference group and $5.4 \%$ in the test group, $\chi^{2}=$ 13.3, $\mathrm{p}<0.05$ ). Therefore, the joint application of HBOT and traditional method in treating acute MI makes it possible to raise the 5-year survival rate from $84.4 \%$ up to $95.9 \%$.

\section{REFERENCES}

[1] Dutta, P., Courties, G., Wei, Y., Leuschner, F., Gorbatov, R., Robbins, C.S., Iwamoto, Y., Thompson, B., Carlson, A.L., Heidt, T., Majmudar, M.D., Lasitschka, F., Etzrodt, M., Waterman, P., Waring, M.T., Chicoine, A.T., van der Laan, A.M., Niessen, H.W., Piek, J.J., Rubin, B.B., Butany, J., Stone, J.R., Katus, H.A., Murphy, S.A., Morrow, D.A., Sabatine, M.S., Vinegoni, C., Moskowitz, M.A., Pittet, M.J., Libby, P., Lin, C.P., Swirski, F.K., Weissleder, R. and Nahrendorf, M. (2012) Myocardial infarction accelerates atherosclerosis. Nature, 487, 325-329. http://dx.doi.org/10.1038/nature11260

[2] Madrigano, J., Mittleman, M.A., Baccarelli, A., Goldberg, R., Melly, S., von Klot, S. and Schwartz J. (2013) Temperature, myocardial infarction, and mortality: Effect modification by individual- and area-level characteristics. Epidemiology, 24, 439-446.

http://dx.doi.org/10.1097/EDE.0b013e3182878397 
[3] Qian, G., Liu, H.-B., Wang, J.-W., Wu, C. and Chen, Y.-D. (2013) Risk of cardiac rupture after acute myocardial infarction is related to a risk of hemorrhage. Journal of Zhejiang University-SCIENCE B (Biomedicine \& Biotechnology), 14, 736-742.

[4] Yeh, R.W., Sidney, S., Chandra, M., Sorel, M., Selby, J.V. and Go, A.S. (2010) Population trends in the incidence and outcomes of acute myocardial infarction. New England Journal of Medicine, 362, 2155-2165.

http://dx.doi.org/10.1056/NEJMoa0908610

[5] van Oeffelen, A.A., Vaartjes, I., Stronks, K., Bots, M.L. and Agyemang, C. (2013) Incidence of acute myocardial infarction in first and second generation minority groups: Does the second generation converge towards the majority population? International Journal of Cardiology, 168, 5422-5429. http://dx.doi.org/10.1016/j.ijcard.2013.08.046

[6] Laatikainen, T., Critchley, J., Vartiainen, E., Salomaa, V., Ketonen, M. and Capewell, S. (2005) Explaining the decline in coronary heart disease mortality in Finland between 1982 and 1997. American Journal of Epidemiology, 162, 764-773. http://dx.doi.org/10.1093/aje/kwi274

[7] Capewell, S., Unal, B., Critchley, J.A. and McMurray, J.J.V. (2006) Over 20000 avoidable coronary deaths in England and Wales in 2000: The failure to give effective treatments to many eligible patients. Heart, 92, 521-523. http://dx.doi.org/10.1136/hrt.2004.053645

[8] Murphy, N.F., MacIntyre, K., Stewart, S., Capewell, S. and McMurray, J.J.V. (2005) Reduced between-hospital variation in short term survival after acute myocardial infarction: The result of improved cardiac care? Heart, 91, 726-730. http://dx.doi.org/10.1136/hrt.2004.042929

[9] Giorda, C.B., Avogaro, A., Maggini, M., Lombardo, F., Mannucci, E., Turco, S., Alegiani, S.S., Raschetti, R., Velussi, M. and Ferrannini, E. (2008) Recurrence of cardiovascular events in patients with type 2 diabetes. $\mathrm{Di}$ abetes Care, 31, 2154-2159.

[10] Launbjerg, J., Fruergaard, P., Madsen, J.K., Mortensen, L.S. and Hansen, J.F. (1994) Ten year mortality in patients with suspected acute myocardial infarction. British Medical Journal, 308, 1196-1199. http://dx.doi.org/10.1136/bmj.308.6938.1196

[11] Goldberg, R.J., Yarzebski, J., Lessard, D. and Gore, J.M. (1999) A two-decade (1975-1995) long experience in incidence, in-hospital and long term case-fatality rates of acute myocardial infarction: A community-wide perspective. Journal of the American College of Cardiology, 33, 1533-1539. http://dx.doi.org/10.1016/S0735-1097(99)00040-6

[12] Capewell, S., Livingston, B.M., MacIntyre, K., Chalmers, J.W., Boyd, J., Finlayson, A., Redpath, A., Pell, J.P., Evans, C.J. and McMurray, J.J. (2000) Trends in casefatality in 117718 patients admitted with acute myocardial infarction in Scotland. European Heart Journal, 21, 1833-1840. http://dx.doi.org/10.1053/euhj.2000.2318

[13] Ulvenstam, G., Aberg, A., Bergstrand, R., Johansson, S., Pennert, K., Vedin, A., Wedel, H., Wilhelmsen, L. and Wilhelmsson, C. (1985) Recurrent myocardial infarction. 1. Natural history of fatal and non-fatal events. European Heart Journal, 6, 294-302.
[14] Ulvenstam, G., Åberg, A., Pennert, K., Vedin, A., Wedel, H., Wilhelmsen, L. and Wilhelmsson, C. (1985) Recurrent myocardial infarction, 2: Possibilities of prediction. European Heart Journal, 6, 303-311.

[15] Madsen, J.K., Grande, P., Saunamäki, K., Thayssen, P., Kassis, E., Eriksen, U., Rasmussen, K., Haunsø, S., Nielsen, T.T., Haghfelt, T., Fritz-Hansen, P., Hjelms, E., Paulsen, P.K., Alstrup, P., Arendrup, H., Niebuhr-Jørgensen, U. and Andersen, L.I. (1997) Danish Multicenter randomized study of invasive versus conservative treatment in patients with inducible ischemia after thrombolysis in acute myocardial infarction (DANAMI). Circulation, 96, 748-755. http://dx.doi.org/10.1161/01.CIR.96.3.748

[16] Vaccarino, V., Berkman, L.F. and Krumholz, H.M. (2000) Long-term outcome of myocardial infarction in women and men: A Population Perspective. American Journal of Epidemiology, 152, 965-973. http://dx.doi.org/10.1093/aje/152.10.965

[17] Nikulina, N.V., Dotsenko, E.A., Salivonchyk, D.P., Welcome, M.O., Lappo, O.G., Dotsenko, K.E. and Bobkov V.Ya. (2013) Low doses hypoxia effectively reduces the size of necrosis in rats with experimental myocardial infarction. World Journal of Medical Sciences, 9, 88-92.

[18] Nylander, G., Nordström, H., Franzén, L., Henriksson, K.-G. and Larsson, J. (1988) Effect of hyperbaric oxygen treatment in post-ischemic muscle: A quantitative morphological study. Scandinavian Journal of Plastic and Reconstructive Surgery and Hand Surgery, 22, 31-39. http://dx.doi.org/10.3109/02844318809097932

[19] van Poucke, S., Jorens, P. and Beaucourt, L. (2006) Physiological effects of hyperbaric oxygen on ischemia reperfusion phenomenon. In: Mathieu, D., Ed., Handbook on hyperbaric Medicine, Springer, Berlin, 121-134. http://dx.doi.org/10.1007/1-4020-4448-8 8

[20] Tabrah, F.L., Tanner, R., Vega, R. and Batkin, S. (1994) Baromedicine today-Rational uses of hyperbaric oxygen therapy. Hawaii Medical Journal, 53, 112-119.

[21] Wattle, F. (2006) A history of hyperbaric medicine. In: Mathieu, D., Ed., Handbook on Hyperbaric Medicine, Springer, Berlin, 1-11. http://dx.doi.org/10.1007/1-4020-4448-8_1

[22] Ingle, R. (1990) Hyperbaric oxygen therapy. Journal of the American Medical Association, 264, 1811. http://dx.doi.org/10.1001/jama.1990.03450140031024

[23] Yin, X., Meng, F., Wang, Y., Wei, W., Li, A., Chai, Y. and Feng, Z. (2013) Effect of hyperbaric oxygen on neurological recovery of neonatal rats following hypoxicischemic brain damage and its underlying mechanism. International Journal of Clinical and Experimental Pathology, 6, 66-75.

[24] Efrati, S., Fishlev, G., Bechor, Y., Volkov, O., Bergan, J., Kliakhandler, K., Kamiager, I., Gal, N., Friedman, M., Ben-Jacob, E. and Golan, H. (2013) Hyperbaric oxygen induces late neuroplasticity in post stroke patients-Randomized, prospective trial. PLOS ONE, 8, e53716. http://dx.doi.org/10.1371/journal.pone.0053716

[25] Clower, J.H., Hampson, N.B., Iqbal, S. and Yip, F.Y. (2012) Recipients of hyperbaric oxygen treatment for carbon monoxide poisoning and exposure circumstances. 
American Journal of Emergency Medicine, 30, 846-851. http://dx.doi.org/10.1016/j.ajem.2011.05.028

[26] Rossignol, D.A. (2012) Hyperbaric oxygen treatment for inflammatory bowel disease: A systematic review and analysis. Medical Gas Research, 2, 6. http://dx.doi.org/10.1186/2045-9912-2-6

[27] Leach, R.M., Rees, P.J. and Wilmshurst, P. (1998) ABC of oxygen: Hyperbaric oxygen therapy. British Medical Journal, 317, 1140-1143. http://dx.doi.org/10.1136/bmj.317.7166.1140

[28] Stavitsky, Y., Shandling, A.H., Ellestad, M.H., Hart, G.B., Van Natta, B., Messenger, J.C., Strauss, M., Dekleva, M.N., Alexander, J.M., Mattice, M. and Clarke, D. (1998) Hyperbaric oxygen and thrombolysis in myocardial infarction: The "HOT MI" randomized multicenter study. Cardiology, 90, 131-136. http://dx.doi.org/10.1159/000006832

[29] Schmutz, J. (2006) Myocardial infarction. In: Mathieu, D., Ed., Handbook on Hyperbaric Medicine, Springer, Berlin, 591-595. http://dx.doi.org/10.1007/1-4020-4448-8_35

[30] European Society of Cardiology, American College of Cardiology (2002) Myocardial infarction redefined-A consensus document of the joint European Society of Cardiology/American College of Cardiology committee for the redefinition of myocardial infarction. European Heart Journal, 21, 1502-1513.

[31] Ferguson, J.L., Beckett, G.J., Stoddart, M., Walker, S.W. and Fox, K.A. (2002) Myocardial infarction redefined: The new ACC/ESC definition, based on cardiac troponin, increases the apparent incidence of infarction. Heart, 88, 343-347. http://dx.doi.org/10.1136/heart.88.4.343

[32] Report of the Joint International Society and Federation of Cardiology/World Health Organization Task Force on Standardization of Clinical Nomenclature (1979) Nomenclature and Criteria for Diagnosis of Ischemic Heart Disease. Circulation, 59, 607-609. http://dx.doi.org/10.1161/01.CIR.59.3.607

[33] Roe, M.T., Parsons, L.S., Pollack Jr., C.V., Canto, J.G., Barron, H.V., Every, N.R., Rogers, W.J. and Peterson, E.D. (2005) Quality of care by classification of myocardial infarction: Treatment patterns for ST-segment elevation vs non-ST-segment elevation myocardial infarction. Archives of Internal Medicine, 165, 1630-1636. http://dx.doi.org/10.1001/archinte.165.14.1630

[34] Dotsenko, E.A., Salivonchyk, D., Nikulina, N. and Welcome, M.O. (2009) The influence of hyperbaric oxygenation therapy on recurrent myocardial infarction and twoyear survival rate with acute myocardial infarction patients. Port-Harcourt Medical Journal, 3, 256-263. http://dx.doi.org/10.4314/phmedj.v3i3.45267

[35] Lai, T., Fallon, J.T., Liu, J., Mangion, J., Gillam, L., Waters, D. and Chen C. (2000) Reversibility and pathohistological basis of left ventricular remodeling in hibernating myocardium. Cardiovascular Pathology, 9, 323-335. http://dx.doi.org/10.1016/S1054-8807(00)00052-1

[36] Imperatore, F., Cuzzocrea, S., De Lucia, D., Sessa, M., Rinaldi, B., Capuano, A., Liguori, G., Filippelli, A. and Rossi, F. (2006) Hyperbaric oxygen therapy prevents coagulation disorders in experimental model of multiple organ failure syndrome. Intensive Care Medicine, 32, 1881-1888. http://dx.doi.org/10.1007/s00134-006-0367-3

[37] dos Santos, L., Serra, A.J., Antônio, E.L., Hull, H.F. and Tucci, P.J. (2009) Hyperbaric oxygenation applied immediately after coronary occlusion reduces myocardial necrosis and acute mortality in rats. Clinical and Experimental Pharmacology and Physiology, 36, 594-598. http://dx.doi.org/10.1111/j.1440-1681.2008.05118.x

[38] Mathieu, D., Mathieu-Nolf, M., Linke, J.C., Favory, R. and Wattel, F. (2006) Carbon monoxide poisoning. In: Mathieu, D., Ed., Handbook on Hyperbaric Medicine, Springer, Berlin, 239-261. http://dx.doi.org/10.1007/1-4020-4448-8_14

[39] Kim, C.H., Choi, H., Chun, Y.S., Kim, G.T., Park, J.W. and Kim, M.S. (2001) Hyperbaric oxygenation pretreatment induces catalase and reduces infarct size in ischemic rat myocardium. Pflügers Archiv: European Journal of Physiology, 442, 519-525.

[40] Kim, S., Yukishita, T., Lee, K., Yokota, S., Nakata, K., Suzuki, D. and Kobayashi, H. (2011) The effect of mildpressure hyperbaric therapy (Oasis O2) on fatigue and oxidative stress. Health, 3, 432-436. http://dx.doi.org/10.4236/health.2011.37071

[41] Bennett, M.H., Lehm, J.P. and Jepson, N. (2011) Hyperbaric oxygen therapy for acute coronary syndrome. Cochrane Database of Systematic Reviews, 8, CD004818. 